\title{
A ESPIRITUALIDADE EM LOGOTERAPIA E ANÁLISE EXISTENCIAL: O ESPÍRITO EM UMA PERSPECTIVA FENOMENOLÓGICA E EXISTENCIAL
}

\author{
The Spirituality in Logotherapy and Existential Analysis: The spiritual in a phenomenological \\ and existential perspective
}

\author{
La espiritualidad en Logoterapia y Análisis Existencial: El Espíritu en una perspectiva \\ fenomenológica y existencial
}

VALDiR BARBOSA LiMA NeTO

\begin{abstract}
Resumo: O artigo visa abordar o conceito de espírito em Logoterapia e Análise Existencial, contemplando a visão ontológica e a antropologia filosófica elaborada por Viktor Emil Frankl sobre tal conceito, bem como os principais fundamentos e pensadores que embasam e dialogam com as ideias do referido autor. O trabalho visa esclarecer e aprofundar a dimensão noética ou espiritual do homem, tomando-o como a pedra angular da terapia do sentido. Enfocando a importância de compreender o espírito do homem dentro de uma visão antropológica para desenvolver uma humanização da ciência psicológica e da psicoterapia, bem como promover uma compreensão adequada da perspectiva e da metodologia logoterápica. O artigo contemplará uma breve introdução no contexto histórico no qual Frankl propõe como uma psicologia que abrange o estudo da pessoa espiritual, em seguida será abordado o conceito de espírito na ótica logoterápica, bem como sua fundamentação fenomenológica e existencial. Depois será aprofundada a questão da dimensão noética, explicitando a abordagem e suas principais fundamentações metodológicas, esclarecendo questões importantes a respeito da categoria espiritual, concluindo a relevância do conceito de espírito para a compreensão da Logoterapia e para a Análise Existencial, bem como para a uma prática humanizada em psicoterapia e em Psicologia como um todo.
\end{abstract}

Palavras-chave: Logoterapia; Espírito; Humanização.

Abstract: This paper aims to address the concept of spirit in Logotherapy and Existential Analysis, issuing the ontological vision and the philosophical anthropology developed by Viktor Emil Frankl on this concept, as well as the theoretical foundations and key thinkers who gave support to the author's ideas. The work aims to clarify and deepen the theory behind the spiritual or noetic dimension of man, understanding it as the cornerstone of a meaning-centered therapy. Focusing on the importance of understanding man's spirit within an anthropological view for the humanization of the psychotherapy and the psychological science, promoting a proper understanding of the Logotherapy's comprehension and methodology. The article will include a brief introduction about the historical context in which Frankl proposes a psychology school that covers the study of the spiritual person, then we will address the concept of spirit in Logotherapy's perspective, as well as its phenomenological and existential foundations. Then the question of the noetic dimension will be depeened, as we will cover the logotherapeutic approach and its main methodological foundations, clarifying important questions about the spiritual category, concluding the relevance of the concept of spirit for understanding the Logotherapy and Existential Analysis, as well as the humanization practice in psychotherapy and in psychology as a whole.

Keywords: Logotherapy; Spirit; Humanization.

Resúmen: El artículo pretende abordar el concepto del espíritu en la Logoterapia y en la Análisis Existencial, contemplando la visión ontológica y la antropología filosófica desarrollada por Viktor Emil Frankl en este concepto, así como los principales pensadores y fundaciones que apoyan y que interactúan con las ideas de este autor. El trabajo pretende aclarar y profundizar la dimensión espiritual o noética del hombre, la piedra angular de la constitución de la terapia del sentido, basándose en la importancia de comprender el espíritu del hombre en una visión para la humanización de la ciencia psicológica y psicoterapica, así como para una adecuada comprensión del punto de vista antropológico y de la metodología de la Logoterapia. El artículo incluye una introducción en el contexto histórico en el que Frankl propone una psicología que contiene el estudio de la persona espiritual, después se irá abordar el concepto del espíritu en la vision de la Logoterapia, así como sus fundamentaciones fenomenológicas y existenciales. A continuación vamos a profundizar la cuestión de la dimensión noética, explicando el enfoque logoterapeutica y sus principales fundamentos metodológicos, aclarar cuestiones importantes con respecto a la categoría espiritual, concluyendo la relevancia del concepto de la espíritu para comprender la Logoterapia y Análisis Existencial, así como para una práctica humana en la psicoterapia y la psicología en su conjunto

Palabras-clave: Logoterapia; Espíritu; Humanización. 
O espírito é o único ser que é por si incapaz de ser objetivado - ele é pura atualidade, só tem seu ser na livre realização de seus atos. O centro do espírito, a pessoa, não é, portanto, nem um ser objetivo, nem um ser coisificado, mas apenas uma estrutura ordenadora de atos que leva a tempo constantemente

a si mesmo. A pessoa só é em seus atos e através deles... algo anímico não realiza a si mesmo: ele é uma série de acontecimentos no tempo...tudo o que é anímico é passível de objetivação - mas não o ato

espiritual. Nós só podemos nos reunir ao ser da nossa pessoa, nos concentrar em sua direção - mas não podemos objetivá-lo. Como pessoas não podemos objetivar nem mesmo as outras pessoas.

(Max Scheler, 1928/2003, p. 45)

\section{Introdução}

Logoterapia e Análise Existencial são duas faces da mesma escola de pensamento psicológico e psicoterapêutico. Oriunda de Viena, surgindo no século XX, tendo sua ascensão no período pós-segunda guerra mundial, a abordagem também é conhecida como a terapia do sentido, sendo edificada, sobretudo, a partir do pensamento fenomenológico e das inspirações da filosofia existencial (Frankl, 1987/2012).

A Logoterapia é entendida como o método psicoterapêutico que visa o desdobramento de cada sentido concreto experimentado em cada situação imediata vivencialmente. A Análise Existencial atua como a pesquisa filosófica de Viktor Emil Frankl (1987/2012), fundador da abordagem, que visa fundamentar e embasar sua psicoterapia, de modo que ela se constitua não como uma análise da existência, mas como uma análise dirigida à existência, a fim de enfocar o ser humano em sua dimensão vivida, concreta e, portanto, existencial, uma vez que o sentido, por essa ótica, não é passível do alcance objetivante e explicativo, só sendo atingido de modo vivencial. A palavra logos vem do grego e significa sentido ou o caráter espiritual humano (Frankl, 1987/2012).

Para a construção de tal abordagem em psicologia e em psicoterapia, Frankl (1972/2011) esforçou-se em elaborar uma antropologia, uma filosofia e uma ontologia que embasasse e norteasse sua prática e sua pesquisa psicológica, uma vez que, para o autor, toda psicoterapia, direta ou indiretamente, tenderia a promover uma visão de homem e de mundo (Frankl, 1972/2011). Nas palavras do próprio Frankl: "Todo conhecimento, na medida em que é um conhecimento humano, está ligado a uma posição" (Frankl, 1987/2012, p. 81). Por essa perspectiva, para se constituir devidamente uma teoria psicoterápica, é fundamental expor os aspectos filosóficos e metodológicos que permeiam a visão de mundo pressuposta por toda prática psicoterapêutica proposta. Através de sua ótica antropológica, o criador da Logoterapia compreendia o ser humano como um ser espiritual, que escapa a qualquer redução ôntica, "coisificada" ou objetiva, ocupando uma posição privilegiada dentre os demais entes do mundo (Heidegger, 1927/2009; Frankl, 1987/2012). O homem é o ser capaz de vivenciar e desvelar sentidos, um ser, que além de uma dimensão ôntica, apresenta uma dimensão ontológica (Fonseca, 2006; Heidegger, 1927/2009). Por meio de uma perspectiva de homem enquanto ser ontológico e espiritual, o conceito de espírito ocupa um lugar fundamental para o entendimento da Logoterapia e da Análise Existencial, uma vez que é no voltar-se ao caráter espiritual do ser-homem que Viktor Frankl promove seu método do encontro de sentidos. Conhecer devidamente o modo como a Logoterapia aborda o conceito de espírito torna-se imprescindível para todos aqueles que desejam explorar as possibilidades da terapia do sentido e compreender a visão de homem da Análise Existencial frankliana.

Este trabalho tentará expor, brevemente, o modo como o conceito de espírito é abordado pela teoria logoterápica, promovendo um diálogo com as principais influências da fenomenologia e das filosofias da existência que fundamentaram os pensamentos de Frankl ao compor a conceituação da dimensão espiritual ou noética (do grego nous, que significa espírito), bem como suas principais implicações na visão e na atuação logoterapêutica. Será, primeiramente, apresentado o contexto no qual Frankl sentiu a necessidade de introduzir uma visão de pessoa espiritual em psicoterapia. Depois, apresentar-se-á a compreensão de espírito a partir da antropologia de Frankl e dos autores influente em tal perspectiva, seguida das principais interseções que o elemento espiritual faz com o inter-humano, com a fenomenologia, com a psicoterapia e com a religiosidade para ajudar no esclarecimento de tal conceito e suas implicações em psicologia, concluindo a relevância em se tematizar o conceito de espiritualidade em Logoterapia e Análise Existencial para o devido entendimento de tal teoria e prática psicoterápica.

\section{A crítica de Viktor Frankl}

Partindo do posicionamento no qual toda psicoterapia seria responsável pela promoção de uma determinada cosmovisão de mundo e de homem, na construção da Logoterapia, Viktor Frankl (1972/2011), médico, psiquiatra e neurologista, realizou uma crítica as duas principais forças psicológicas de seu tempo, acusando-as de reducionistas e niilistas, argumentando que, até então, a psicologia estava tomando como seu objeto de pesquisa apenas uma faceta do homem, limitando a humanidade a este único aspecto, que o autor chamou de caráter factual do ser humano, Frankl(1978/2005) ressalta algumas discordâncias pontuais como os aspectos mecanicistas e o deterministas que, segundo o autor, eram assumidos tanto pelas psicologias do comportamento, quanto pelas psicologias do inconsciente. 
A psicanálise vê a neurose como resultado de certas psicodinâmicas e procura, consequentemente, neutralizá-las suscitando a ação de outras psicodinâmicas... A terapia behaviorista, por sua vez, atribui a neurose a certos processos de aprendizagem ou de condicionamento e, consequentemente, prescreve novas aprendizagens e novos condicionamentos para neutralizá-la... Em ambos os casos a terapia permanece no âmbito da neurose. A logoterapia, ao contrário... Vai além desse plano, seguindo o homem na dimensão humana onde ele pode alcançar os recursos que, apenas aí estão disponíveis (Frankl, 1978/2005, p. 9).

Por um lado, o homem era visto como um organismo imerso em um ambiente de estímulos e contingências que o condicionam a agir, pensar e sentir, eis o legado do behaviorismo. Por outro lado, a psicanálise percebia o homem constituído de um aparato psíquico que era regido por leis energéticas e mecânicas, tais forças internas e inconscientes seriam a causa primeira de todas as ações humanas. O que duas linhas de pensamento, $a$ priori tão distintas teriam em comum? Ambas acreditavam que o ser humano era aprisionado em uma lógica causal. O determinismo ambiental ou pulsional seriam as condições que regiam o homem e para abordá-lo, seria preciso compreender estes determinismos.

Logo, tomando apenas a dimensão determinada do homem, por meio de uma redução ôntica, para se valer das palavras de Martin Heidegger (1927/2009), a ciência psicológica passou a reduzir o ser humano meramente aos aspectos que o condicionam, objetalizando-o (Frankl, 1987/2012). Nesse sentido, segundo o criador da Logoterapia, o ser humano sofrera uma verdadeira "coisificação" no início do percurso da psicologia científica e da psicoterapia, herança do legado técnico-científico e do paradigma positivista. Tal dimensão ôntica havia sido supervalorizada pelas escolas estudiosas do inconsciente, com toda sua perspectiva pulsional e psicodinâmica do psiquismo humano e pelas escolas pesquisadoras do comportamento, elegendo o comportar-se como o único foco de estudo possível para se chegar a um conhecimento válido e preciso sobre a psique.

Uma psicologia... que se orienta pelo modelo metodológico das ciências naturais, se comprometem com uma falsificação, com uma desnaturalização, e com uma desumanização do sujeito humano, na medida em que este sujeito, submetido à observação, se transforma, inevitável em objeto (Frankl, 1981/1990, p. 35)

O determinismo e o mecanicismo também se faziam fortemente presente no pensamento psiquiátrico e na visão biomédica nos tempos de Frankl. O aparato biológico, a genética e a hereditariedade, nesse sentido, seriam a fonte que gerava e explicava todo o homem. Mais uma vez, o determinismo se fazia presente e, a ótica causal se apresentava como a lógica possível para se atuar com esta perspectiva de ser humano. Sobre esse pensamento, Frankl (1978/2005) afirmava: A hereditariedade é simplesmente o material com o qual o homem constrói a si mesmo. Não se trata senão de pedras que são rejeitadas e jogadas fora pelo construtor, ou não. Mas o construtor como tal não é feito de pedras (p. 44).

Contudo, de uma maneira geral, essas duas forças do pensamento psicológico do início do século XX, bem como a visão "biologizante" da psiquiatria clássica, compreendiam que o ser humano é um ser determinado, seja por forças internas do um inconsciente obscuro ou por forças externas estimuladoras de comportamentos adaptativos ou mesmo resultantes de uma carga genética hereditária. Instrumentalizadas a partir do método positivista, tanto a Psicanálise quanto as escolas comportamentais passaram a objetificar o ser humano no intuito de entendê-lo e explicá-lo. A proposta terapêutica que emerge de tais abordagens é a de um analista, seja dos conteúdos inconscientes seja dos comportamentos humanos, que toma a pessoa em terapia como objeto a ser analisado e interpretado (Lima Neto, 2012).

Além dos aspectos deterministas, mecanicistas e reducionistas, Frankl (1946/1989) também criticara o niilismo presente no pensamento dos behavioristas e dos psicanalistas, que compreendiam, de um lado, que o mundo é um meio para a satisfação de desejos e pulsões (tese defendida pela Psicanálise freudiana), e de outro, que o mundo é um contexto contingencial que determina como o ser humano age e pensa, bem como afirmam as linhas de inspirações Behavioristas. Nas duas teses, o mundo é um estranho indiferente e frio às inquietações do homem que sofre e questiona-se a respeito do sentido da vida e de suas dores. Nas duas perspectivas, falar de liberdade e de sentido é falar de ilusões construídas pelo homem e projetadas no mundo para tornar a existência humana, na medida do possível, um pouco mais suportável (Frankl,1972/2011).

\section{A proposta logoterápica}

Frankl (1972/2011) acreditava que as principais linhas psicológicas de sua época bem como a visão médica e psiquiátrica, estavam negligenciando o aspecto genuinamente humano do homem, recorrendo a metodologias e teorias que o reduziam a um único faceta de sua complexidade e de sua pluralidade, na intenção de determiná-lo e explicá-lo, caindo em uma perspectiva limitadora das possibilidades exclusivamente humanas. Para o autor seria necessária uma concepção de homem e de mundo, diferente das tradicionais psicoterapias de sua época, para então estruturar-se uma teoria e uma prática que inclua o ser humano em sua totalidade, em sua pluralidade unificada e significativa, em sua singularidade integralmente humana. Portanto, para a construção de uma abordagem 
em psicologia, segundo Frankl (1987/2012), como atentado anteriormente, é fundamental o embasamento em uma antropologia filosófica para constituir um método psicológico. Não por acaso que as críticas do autor às escolas psicológicas de seu tempo já se mostram permeadas pela sua própria compreensão antropológica, a “ontologia dimensional": que teoriza a possibilidade de enxergar o homem sob diferentes dimensões que o compõem e o integram como uma alteridade irredutível.

Ao acusar os comportamentais e psicanalistas de estarem reduzindo o ser humano a um único aspecto de sua totalidade unificada na pluralidade, Frankl (1946/1989) parte da premissa de que o homem apresenta-se em três dimensões principais: somatológica, psicológica e noológica. A dimensão somatológica ou somática inclui todo o aspecto fisiológico do homem, tematizando a visão biológica e orgânica do ser humano. A dimensão psicológica ou psíquica abrange as pulsões, bem como o funcionamento psicodinâmico do psiquismo, os comportamentos operantes, os processos psicológicos, etc. Para Frankl, essas duas primeiras dimensionalidades da pessoa caracterizariam o aspecto factual, determinado e passível de ser explicado objetivamente. Diferindo destas duas dimensões ou deste referido caráter determinista da condição humana, aparece a dimensão noológica, também nomeada de espiritual. É a dimensão na qual o homem opera em uma realidade existencial, presentificada no momento criador e recriador de si mesmo em sua relação com o mundo. Esta seria a dimensão que contemplaria devidamente o ser humano, plena de valores e sentidos concretos, o aspecto no qual se reconhece a validade da liberdade, da responsabilidade e da consciência. Exatamente aquela dimensão que, segundo Frankl (1978/2005), estava sendo negligenciada pelas psicologias do começo do século XX.

Portanto, a grande crítica de Frankl (1972/2011) dirigiu-se à indiferença para com o elemento espiritual por parte dos psicólogos de seu tempo. Resgatar o aspecto espiritual, bem como promover um método de atuação para o espírito e a partir dele é exatamente a proposta logoterapêutica. Para compreendê-la, faz-se imprescindível o devido entendimento de tal conceito em Frankl, calcados em embasamentos filosóficos, antropológicos e psicológicos.

\section{A dimensão espiritual na antropologia frankliana}

Como já enfatizado anteriormente, Frankl (1987/2012) parte de uma sólida fundamentação filosófica para elaborar sua concepção de homem e de espírito. O pensamento de Max Scheler (1928/2003), filósofo inserido na linha fenomenológica, é, sem dúvida, um dos principais pilares de seu pensamento antropológico. Outros pensadores como Martin Heidegger (1927/2009), Nicolai Hartmann (1949/1975), Martin Buber (1923/2010), entre outros nomes importantes de estudiosos da fenomenologia-existen- cial, comporiam os outros pilares que integram a visão de homem da Análise Existencial frankliana. O diálogo com esses vários autores só aumenta a singularidade do pensamento de Frankl, que não se limita a uma mera reprodução e aplicação das ideias de alguns filósofos, psiquiatras e psicólogos à psicologia, mas sim, na criação de um autêntico pensamento filosófico, antropológico e psicológico, a partir de uma fundamentação consistente.

É, sobretudo, por meio das contribuições das ideias de Scheler (1928/2003), que o conceito de espírito se insere na obra de Frankl (1987/2012). O pensamento scheleriano aborda o homem enquanto um ser espiritual. Esse fato antropológico, por sua vez, destacaria o ser humano dentre todos os outros seres na natureza. Enquanto os animais compartilhariam com o homem aspectos semelhantes como: impulso afetivo, instintos, memória associativa e inteligência prática, denominadas por Scheler(1928/2003) de "as quatro formas essenciais da vida", o homem apresentaria algo qualitativamente diferente a todo e qualquer outro ser na natureza, o chamado aspecto espiritual.

Mas que diferenças seriam essas que se apresentariam a partir desse novo aspecto? Scheler, como mostrado anteriormente, observara a presença de características "animais" no homem. Coexistindo com o caráter anímico, que abrangeria os instintos, as pulsões e tudo o que "naturalmente" condicionam e determinam o homem, haveria também os elementos espirituais, que se diferenciariam daquilo que é entendido como vida no seu sentido "natural”, ressaltando-se aos aspectos anímicos. Enquanto na realidade anímica o homem é impulsionado por algo, colocando o ser humano num paradigma de causa e efeito, a realidade espiritual situa-se inteiramente no âmbito da atualidade. O espírito é ato puro, é presença que só se manifesta no momento em que se realiza, no instante do “aqui e agora" (Scheler, 1928/2003; Buber, 1923/2010). Nessa perspectiva, o espírito inserir-se-ia no âmbito do possível, da possibilidade ascendente que se desdobra e se instala na realidade. Uma atitude Eu-Tu, ontológica dimensão do possível em desdobramento que tende a se realizar e, então, converte-se em um Eu-Isso, dimensão da própria instalação do real (Heidegger, 1927/2009; Buber, 1923/2010). É algo que caracteriza a liberdade e a consciência humana imediata, instantânea, vivida diante do mundo e da própria realidade, um acontecimento que se configura, em toda a sua extensão, como sentido. Nas palavras de Frankl:

Trata-se em particular de fazer qualquer coisa em relação à situação na qual nos encontramos para modificar, se for necessário, a realidade. Desde que a situação é sempre única, com um sentido que também é necessariamente único, segue-se que a "possibilidade de fazer qualquer coisa em relação à situação" é também única, porque é transitória. Ela possui uma qualidade kairos, isto é, se não aproveitamos a oportunidade de dinamizar o sentido intrínseco e como 
que mergulhando na situação, o sentido passará e irá embora para sempre (Frankl, 1978/2005, p. 32).

Nessa ótica, o caráter espiritual é o elemento que permite o desdobramento de sentido, caracterizando o ser humano enquanto possibilidade, se diferenciando de tudo o que o determina, o espírito ressalta a capacidade humana de transcender a toda cadeia determinante, a todo meio que condiciona, possibilitando que o homem espiritual torne tudo alvo de ação para si, inclusive sua própria natureza anímica (Scheler, 1928/2003). As coisas, as criaturas, são determinadas, são seres do passado, condicionados a reprodução do padrão da instalação do real. O elemento espiritual é sempre novo, atual, criação, ele guarda uma relação intrínseca com o imediato, com a instantaneidade reveladora e imprevisível do momento (Buber, 1923/2010). O fator espiritual ressalta a capacidade de decisão do homem, uma vez que este passa a agir, não apenas inteiramente impulsionado por seus conteúdos anímicos, mas também orientado por sua espiritualidade. $\mathrm{O}$ anímico apresenta-se factualmente, porém, toda a dimensão espiritual se dá facultativamente, enquanto uma escolha autêntica e vivida (Frankl 1972/2011; 1987/2012).

É importante frisar a relação intrínseca existente entre o anímico e o espiritual destacada por Scheler (1928/2003), pois, partindo da compreensão de que toda forma de ser mais elevada apresenta, necessariamente, menos força e mais dependência em relação às formas menos elevadas, o filósofo entendia que o espírito não tem nenhuma força em si mesmo, na verdade, ele necessita do impulso anímico, que sendo uma dimensão inferior à dimensão do espírito, apresentaria mais independência e mais poder a partir da força das pulsões e dos instintos para agir na pessoa espiritual. Na tentativa de ilustrar tal ideia, lembremo-nos do sábio verso de "O Profeta”, de Kahlil Gribran:

A vossa razão e a vossa paixão são o leme e as velas da vossa alma navegante. Se um de vós navegar e as velas se partirem, só podereis andar à deriva ou ficar imóveis no meio do mar. Pois a razão, por si só, reprimi toda pulsão; e a paixão, não controlada, é chama que arde até a sua própria destruição (Gibran, 1923/2010, p. 38).

Analogamente à metáfora de Gibran, a razão representaria o espírito que opera como o leme, e as paixões estariam na mesma posição que o anímico que, como as velas de um barco, ou sendo o motor de um navio, empurram e impulsionam a pessoa através das águas da existência. Nossa alma navegante, como chamou o escritor, precisaria tanto das velas e dos motores quanto do leme, o anímico é o motor da alma e o espírito seu guia e seu orientador. Diante do desejo pulsional, que é a pura força que move, surge a vontade do espírito para guiar a alma navegante, a pessoa espiritual. Scheler não tem a inten- ção de negar ou reprimir o anímico na sua visão de ser humano, mas reconhece a pulsionalidade como constituinte do homem e como força fundamental para o espírito emergir. Tal qual na metáfora de Gibran, anímico e espiritual são duas facetas da alma humana, da pessoa espiritual. A alma navegante representaria a pessoa, do latim personare, que significa soar através, representando o conceito de pessoa como um ordenador de atos intuitivos e conscientes, aquela por meio do qual soa o sopro do espírito, que leva a prova a si mesma em cada ato espiritual e intencional (Scheler, 1928/2003; Buber, 1923/2010).

\section{0 espiritual em uma perspectiva fenomenológica, existencial e dialógica}

Ao discorrer sobre as características do espírito, Frankl (1946/1989) considera o pressuposto dialógico (Dia: compartilhamento, Logos; sentido) fundamental, no qual tudo que "é", existe em compartilhamento, no qual o princípio da existência é a relação. Martin Buber (1923/2010), principal expoente do estudo dialógico, afirmou que é no relacionar-se que o Eu se constitui, ou seja, o homem se torna Eu diante do Tu. O mundo e o outro se dão como condições de existência, como cooriginários no surgimento da humanidade. Martin Heidegger (1927/2009), enfatizou que o Dasein, termo que o filósofo designou para ressaltar o ser humano em sua dimensão existencial, é sempre um "ser-com", e, portanto, um "ser-com-o-outro" e um "ser-no-mundo". O homem existencial, enquanto ação, enquanto presença, portanto, o Dasein, já se dá em uma coexistência com demais alteridades no mundo. Frankl (1946/1989) afirma que o ser-homem é um "ser-referido", logo, um ser em relação, pois é só na relação que o ser existe, diferencia-se, destaca-se, particulariza-se e torna-se único e singular. Portanto, entende-se o elemento espiritual em Logoterapia como a característica essencial da dimensão existencial do homem. Nesse sentido, divergindo das tradicionais visões psicológicas mencionadas anteriormente, o mundo, na compreensão logoterápica, não é algo indiferente ao homem, que surge como um natural absurdo. Mas sim um Tu que se relaciona intrinsecamente e constantemente com o Eu espiritual, ambos se constituindo e afetando-se reciprocamente. $\mathrm{O}$ mundo responde ao Eu espiritual e nessa premissa o espírito é sempre um "estar-junto-a", existindo necessariamente em relação concreta e direta com o mundo (Frankl, 1987/2012). A qualidade deste "estar-junto-a" é existir sempre entrelaçado com o outro, com o Tu, seja este outro, como atentou Buber(1923/2010), a natureza e os objetos naturais, outros seres humanos ou até mesmo o absoluto, esta é a qualidade dialógica da pessoa espiritual. A condição dialógica é indispensável para o entendimento do espírito, pois, reafirmando, este se dá sempre e de certa maneira, exclusivamente, em relação (Frankl, 1987/2012). 
O espírito em sua manifestação humana é a resposta do homem ao seu Tu... Este espírito é a resposta ao Tu que se revela dos mistérios, e que do seio desde mistério o chama. O espírito é palavra. O espírito não está no Eu, mas entre o Eu e o Tu. Ele não é comparável ao sangue que circula em ti, mas ao ar que respiras. O homem vive no espírito na medida em que pode responder ao seu Tu. Ele é capaz disso quando entra na relação com todo o seu ser. Somente em virtude de seu poder de relação que o homem pode viver no espírito (Buber, 1923/2010, p. 75).

Tais considerações a respeito do espiritual já revelam influências diretas da fenomenologia. A compreensão do princípio relacional dialoga diretamente com o conceito de intencionalidade cunhado por Franz Brentano (1874/1935), no qual a consciência é cooriginária ao mundo, só existindo um mundo para uma consciência, e, mutuamente, só havendo uma consciência em relação a um mundo. Husserl (1973/2008), conhecido como o fundador da fenomenologia, carregou consigo tal conceito ao falar do "a priori da correlação”, lançado ao mundo a grande herança de Brentano à fenomenologia, o princípio relacional, a qualidade empírica e concreta da consciência em seu estado “puro”, fenomenal, que se dá no mundo enquanto vivência.

Frankl (1987/2012) teve fortes inspirações a partir de tais ideias, sobretudo por influências diretas da fenomenologia de Scheler (1928/1986) que, por meio do contato com Husserl e Brentano, afirmou a importância do aspecto intuitivo e experiencial da consciência vivida empiricamente. O que se faz compreender que esse estar em relação, o "ser-junto" como escreveu Frankl, se dá como consciência, como cognição, como compreensão vivencial, pré-reflexiva, estabelecida concretamente (Fonseca, s.d.).

O que é, então, em ultima instância, esse ser-junto-a do espiritualmente ente? Trata-se da intencionalidade desse ente que é de maneira espiritual! O ente que é espiritualmente, porém, é intencional no fundo de sua essência, e, assim, é possível dizer: um ente que é de maneira espiritual é espiritualmente ente, é um ser-consciente, é "junto a si” a medida que "é” junto a um outro ente - à medida que "se conscientiza" de um outro ente. Com isso, o espiritualmente ente se realiza no ser-junto-a, assim como esse ser-junto-a do ser espiritual é a sua possibilidade mais originariamente própria, sua capacidade propriamente dita (Frankl, 1987/2012, pág.75).

Frankl (1946/1989) anunciara que o cerne antropológico do ser humano sintetiza-se em um binômio: ser-consciente e ser-responsável. Agora, já após algumas explicitações a respeito do conceito de espírito, faz-se entender a profundidade de seu anúncio. Uma vez que o homem é sempre em intencionalidade no mundo, logo, em relação constante, esse se relacionar dá-se como consciência. Ao mesmo tempo em que a relação é sempre uma ação, uma resposta do Eu ao Tu em todo desdobramento do possível. Ser-consciente e ser-responsáveis são duas faces da pessoa humana, duas características ontológicas do modo de ser humano, pois toda resposta do homem, toda afirmação da vida é consciente, assim como também toda consciência se dá na afirmação da vida, na resposta da palavra princípio Eu-Tu (Fonseca, s.d.; Buber, 1923/2010).

\section{0 espiritual e a metodologia fenomenológica em logoterapia}

As influências fenomenológicas expostas até então se sintonizam inteiramente com a perspectiva antropológica de Frankl (1978/2005), uma vez que as próprias bases teóricas do autor vieram de pensadores que se situam na vertente da fenomenologia. Essa aproximação é compreendida pelo fato de que a única forma capaz de alcançar o espírito seria, de fato, por meio da captação do dado da experiência imediata. Uma vez que o espírito é compreendido como sendo pura atualidade, apenas de um modo que se capte a vivencia do momento seria possível tematizar a dimensão espiritual, o que aponta diretamente para o método fenomenológico, ou, como também é conhecido na sua apropriação para a psicologia e psicoterapia, o método compreensivo (Figueiredo, 2008).

Já se sabe, até aqui, que a proposta de Frankl foi de construir uma terapia voltada para o caráter espiritual do homem. Já foi visto também que o autor faz uso da fenomenologia tanto enquanto método como quanto fundamento para sua visão antropológica. Dialogando com vários autores, o fundador da Logoterapia construiu uma visão de homem que pretende abranger a dignidade própria da condição humana. Nesse sentido, confirma-se que, como também já explicitado anteriormente, não seria exagero afirmar que conceito de espírito pode ser tomado como a pedra angular da teoria psicológica proposta por Viktor Frankl e que a aproximação com uma perspectiva de atuação fenomenológica justifica-se já na gênese do próprio conceito de espiritual, uma vez que o espírito não pode ser objetivado, determinado, manipulado nem mesmo explicado, sendo a única forma de alcançá-lo, de acordo, por exemplo, com Scheler (1928/2003), seria acompanhando seus atos coparticipativamente.

Só conseguimos conquistar uma participação nas pessoas se acompanharmos a realização e co-realizarmos seus atos livres. Isto só pode ser alcançado através do que é expresso pela mísera palavra "sequaz" ou através daquela “compreensão” que só é possível em meio à postura do amor espiritual, em meio à identificação com o amor, com a vontade de uma pessoa, e, através daí, com ela mesma. Essa compreensão é, por sua vez, o oposto mais extremo de toda objetivação (Scheler, 1928/2003, pág. 46). 
A metodologia fenomenológica em Logoterapia implica no reconhecimento e na afirmação da relação como condição de existência e, portanto, como fundamento ontológico. Focando-se em um encontro existencial que promove a expressão vivencial do cliente, que privilegia um diálogo autêntico e uma dialógica, possibilitando momentos de vivências e experiências de valores que culminam em desdobramento de sentidos.

A "experiência interna" duma vivência simples e isenta de preconceitos teóricos, não nos estará antes a ensinar mais que, por exemplo, a alegria evidente de ver um pôr do sol tem não sei quê de "mais real" do que, digamos, um cálculo astronômico sobre o suposto momento em que a terra virá a chocar contra o sol? Poderá ser-nos dado algo de mais imediato do que a experiência de nós mesmo - a auto-compreensão de nosso ser-homem enquanto ser- responsável? (Frankl, 1946/1989, p. 71)

A ênfase da Logoterapia em possibilitar que o cliente experimente-se como ser-responsável significa exatamente enfatizar uma ação espiritual, pois de que outra forma o espírito se dá, se não por meio da própria ação, de uma vivência coparticipativa e cocriativa com o outro, com o Tu que confirma a própria pessoa espiritual? Privilegiar um ato vivencial, logo, um ato de resposta, é necessariamente possibilitar um momento dialógico, que surge por meio de um encontro, um Eu-Tu, que potencializa o cliente a resignificar a si mesmo por meio do desdobramento de sentido (Buber, 1923/2010). É desse modo que a fenomenologia fundamenta o método logoterapêutico, nomeado aqui como método compreensivo, para diferenciar-se do método explicativo assumido pelas abordagens psicológicas que concebem uma postura analítica, explicativa e interpretativa. A compreensão promove uma postura relacional, que privilegia a experiência vivencial, que se constitui como consciência de sentido por meio do da expressão existencial. Portanto, a Logoterapia, orientada pela Fenomenologia, aparece como uma psicoterapia compreensiva também por ser um método co/apreenviso de sentidos, uma vez que é por meio de um encontro entre duas alteridades, cliente e terapeuta, no qual se apreende significados conjuntamente, na relação e por meio dela. Sentido é, portanto, entendido como uma corealização dos atos espirituais sempre em vivência e em relação dialógica, um dialogo face a face com um Tu, com uma alteridade radical que se disponibiliza a relação e que confirma o Eu correspondente (Fonseca, s.d.). Apresentar-se como tal alteridade na proposta de promover a experiência vivencial imediata do cliente como espiritual, que se configura como vivências e descobrimentos de sentidos, é a postura fenomenológica do logoterapeuta.

\section{Espiritualidade e religiosidade}

Muitos são os mal-entendidos acerca do pensamento frankliano sobre a religiosidade e a espiritualidade. $\mathrm{O}$ autor sempre manteve a preocupação em esclarecer os possíveis desentendimentos a respeito de sua concepção antropológica justamente por abrir-se a uma perspectiva que concebe dimensão espiritual e uma espiritualidade. Ao mesmo tempo, nunca se importou em expressar seu interesse em explorar as possibilidades do espírito, mesmo quando tais possibilidades apontam para uma relação com o sagrado.

O diálogo com a instância do absoluto começa desde a própria compreensão e descrição sobre o que vem a ser o elemento espiritual. Scheler (1928/2003) argumenta que desde o momento em que o ser-homem se destaca de sua condição anímica, e, portanto, alcança uma dimensão existencial, nasce uma necessidade que aponta para um novo norte, além de seu caráter natural. Esse novo horizonte que vem nortear e relacionar-se com a pessoa espiritual é exatamente a dimensão do absoluto, segundo o filósofo.

Exatamente no mesmo instante em que o homem deveniente rompeu os métodos de todo viver animal que lhe era precedente para ser adaptado ao meio ambiente ou para se adaptar a ele, tomando a direção inversa: a adaptação do mundo descoberto a si e à sua vida que se tornou organicamente estável; exatamente no mesmo instante em que o "homem" se arrancou da "natureza" e a tornou objeto de sua dominação e do novo princípio da arte e dos signos: justamente no mesmo instante o homem também precisou ancorar seu centro de algum modo fora e para além do mundo. Ele não podia mais se tomar como uma simples "parte" ou como um simples "membro" do mundo, sobre o qual ele tinha se colocado de maneira tão audaz! (Scheler, 1928/2003, p. 87)

Scheler compreendia que a dimensão da totalidade apresentava-se como horizonte para o qual aponta a transcendência do homem espiritual, como um direcionamento que marca ontologicamente a qualidade cocriativa e corealizadora do espírito com o absoluto, enquanto uma totalidade que se expressa e se realiza com o espírito humano, sobre isso, ele acentua:

A realidade derradeira do ser que existe por si não é passível de objetivação... Só se pode tomar parte em sua vida e de sua realização espiritual através da co-realização, só através do ato de entrega e da identificação ativa. $\mathrm{O}$ ser absoluto não está aí para o apoio do homem, para a mera complementação de suas fraquezas e carecimento que sempre acabam por transformá-lo uma vez mais em "objeto" (Scheler, 1928/2003, p. 90). 
Viktor Frankl (1948/2007) é inspirado pelas considerações de Scheler (1928/2003) a respeito da espiritualidade e da totalidade, bem como por toda a tradição judaica, porém, o pai da Logoterapia pretende afirmar a relação do ser humano com o sagrado, antes de tudo, por um olhar psicológico, além de filosófico. Para Frankl (1948/2007), o entrelaçamento humano com o absoluto se expressa ao nível do sentido, uma vez que o mesmo aborda duas dimensões possíveis para este: a dimensão concreta, a qual a Logoterapia se propõe a dar conta, e a supradimensão, a qual Frankl afirma existir o super sentindo ou o supra sentido. Entendendo o supersentido como um sentido último, que representaria o mosaico de todos os sentidos desdobrados na existência. Segundo Frankl, o sentido constitui-se como uma percepção gestáltica do possível diante do real, em cada situação especifica, uma possibilidade se expressa como sentido que se realiza. $\mathrm{O}$ sentido último seria a configuração de todas as possibilidades realizadas, de todas as gestaltens desdobradas ao longo da existência de uma pessoa particular e, o qual a pessoa estaria direcionada. Seria como se todas as configurações de possibilidade constituídas enquanto gestaltens, e, portanto, enquanto sentidos, reunidas, chegassem à uma ultima configuração. $\mathrm{O}$ horizonte para o qual a autotranscendência humana aponta desde os primeiros sentidos desvelados na vida de cada pessoa. Portanto, em cada primeiro sentido desdobrado, por meio das primeiras palavras princípio Eu-Tu proferidas, pois o próprio desdobramento de sentido dar-se com um momento dialógico, já se mostra presente o Tu eterno. A instância do absoluto surge como horizonte, sempre presente desde o primeiro sopro espiritual da pessoa humana.

Frankl (1948/2007) teoriza que exista uma relação a nível inconsciente, ou ao menos não reflexivo, com a instância do sagrado, de modo ontológico no ser humano. Inspirado pela dialógica de Buber (1923/2010) e pela antropologia filosófica de Scheler (1923/2003), para Frankl existe um nível de consciência pré-reflexiva, que se apresenta uma "realidade de execução", usando as palavras do próprio autor, em que a vivência da relação com o Tu eterno é possível, porém sempre de maneira experienciada e nunca objetivada.

Acreditando que o ser humano está direcionado para o Tu eterno, para o absoluto, para a totalidade, portanto, para o sentindo último, Frankl (1948/2007) faz uma analogia sobre o super sentido tomando-o como um filme rodando no cinema, que é composto por uma série de cenas individuais, que transmitem um sentido situacional o expectador. Para o filme ser entendido, percebido, é necessário passar por todas as cenas até o final. Os sentidos concretos, abordados em Logoterapia, seriam as cenas individuais, e o filme, constituído por todas as cenas, assistido até o seu fim, seria o sentido último. Diante de tal analogia, resgato o sentido das sábias palavras de Buber(1923/2010) sobre o sagrado: "As linhas de todas as relações, se prolongadas, entrecruzam-se no Tu eter- no. Cada tu individualizado é uma perspectiva para ele. Através de cada tu individualizado a palavra-princípio invoca o Tu eterno" (p. 99).

Como já demonstrado acima, o suprasentido é o horizonte para o qual aponta a transcendência originária de todo ser-homem, o Tu eterno presente relacionalmente a toda pessoa espiritual. Ao se deslocar de todo habitat natural, ao destacar-se de todo meio que o condicionasse a partir de sua dimensão anímica, o ser espiritual estranha a si mesmo, questiona a sim mesmo, duvida de seu próprio fundamento. De sua dúvida, ele direciona-se para o absoluto. Geralmente, de acordo com Frankl (1946/1989), o sentido último é desdobrado quando as pessoas encontram-se no final de suas vidas, e a religião é entendida, nesta concepção, como uma forma do homem tentar direcionar-se para este sentido último, que também se mostra como único, singular e relativo a cada pessoa na vivência particular de sua existência (Scheler, 1928/2003; Frankl, 1978/2005).

Portanto, a religiosidade teria, para Frankl (1948/2007), um papel de orientar o direcionamento do homem para seu sentido ultimo, porém, sempre que os valores, costumes, morais e institucionalizações das religiões e igrejas se imporem a frente da relação vivencial e genuína da pessoa espiritual com o absoluto, mais objetivante, "coisificante" e distante da relação ontológica com o sagrado tal religiosidade se apresentará.

A religiosidade... Só é genuína quando existencial, quando a pessoa não é impelida para ela, mas se decide por ela... A religiosidade verdadeira, para que seja existencial, deve ser dado o tempo necessário para que possa brotar espontaneamente (Frankl, 1948/2007, p. 69).

Contudo, a espiritualidade caracterizaria a dimensão eminentemente humana e existencial, aberta e transcendente, que se constitui como consciência e responsabilidade. Esta dimensão relaciona-se com a totalidade, tomando-a enquanto horizonte. Apontando para o absoluto, a relação espiritual originária com o sagrado, essa linguagem que expressa a relação do Eu com o Tu eterno, é o que Frankl entende por religiosidade. Poderia, sinteticamente, ser colocada a espiritualidade como a dimensão propriamente humana que se abre para o mundo e a religiosidade como a qualidade do espírito que está em relação com a totalidade, constituindo-se como a palavra dirigida ao absoluto. Nesse sentido, a espiritualidade e a religiosidade tornam-se questões reconhecidamente humanas para a Análise Existencial e para a Logoterapia, não se constituindo como epifenômenos resultantes de fantasiais ou de projeções do homem para reconfortar a existência, pressuposta sem sentido. Pelo contrário, a relação com a instância do absoluto abre-se como uma categoria ontológica da antropologia frankliana, e é exatamente por um viés filosófico e psicológico que tal diá- 
logo é reconhecido e possibilitado. Retomando a compreensão de supra-sentido, Frankl (1948/2007) entende que a vontade humana não só por um sentido concreto, mas também por um sentido último, constitui-se como a fé religiosa, a fé no supersentido. Logo, a vontade de sentido último, em si, já demonstra a expressão da religiosidade no homem, do direcionamento espiritual para o absoluto.

A compreensão da relação com o sagrado em Frankl (1948/2007) é proposta como um reconhecimento da humanidade e da genuinidade dos fenômenos religiosos, mas nunca como uma aproximação religiosamente institucional valorativa ou mesmo moralista a respeito de sua visão de homem. Sobre isso, Frankl ressalta:

A religião é um fenômeno humano que ocorre no paciente, um entre outros fenômenos com os quais se depara a Logoterapia. Em princípio, entretanto, a existência religiosa e irreligiosa são para a Logoterapia fenômenos coexistentes, e ela tem a obrigação de assumir uma posição neutra perante eles (Frankl, 1948/2007, p. 73)

O enfoque da possibilidade humana em relacionar-se com o absoluto é uma característica inerente ao espírito, e é a este quem Frankl pretende evidenciar na sua escola psicoterápica. Resgatar o elemento espiritual em Psicologia e explorar suas possibilidades: esta é a intenção da Logoterapia. É importante ressaltar as totais incoerências metodológicas e éticas em se utilizar da Logoterapia em psicologia e em psicoterapia de maneira moralistamente religiosa e enviesada, pois tal fato caracterizaria um total desconhecimento dos fundamentos antropológico e metodológicos logoterapêuticos, bem como sérios problemas éticos.

\section{Considerações finais}

Portanto, conclui-se a relevância de se esclarecer o conceito de espírito para a Logoterapia e para a Análise Existencial, uma vez que tal conceito mostra-se como a pedra angular para a compreensão de toda a visão antropológica, para a metodologia e para a própria atuação logoterapêutica. Apresentado-se como uma conceituação psicológica, fundamentada filosoficamente, o elemento espiritual para Viktor Frankl acrescenta à pessoa a sua qualidade e dignidade humana. Essa compreensão abre possibilidades e resignifica a imagem humana no cenário da ciência e as implicações desse feito na prática psicológica são imensuráveis. O reconhecimento da instância espiritual ocorre, em Logoterapia, de maneira filosófica e psicológica, mas de modo algum de forma religiosa no sentido de julgamentos ou moralismos. Tal reconhecimento é potencialmente aberto a incluir no âmbito psicológico os fenômenos espirituais e religiosos, abordando-os de forma fenomenológica e, sobre tudo, psicológica.
Por meio da dimensão noética ou espiritual é que abrem-se as possibilidades para falar de sentidos e valores, liberdade e responsabilidade. Desse modo, a questão espiritual, enquanto um marco ontológico, é o fundamento e, ao mesmo tempo, o próprio “objeto” no qual a Logoterapia se edifica e se direciona no campo da Psicologia. É por meio da dimensão noética e da ressignificação da visão de homem que esta promove em Psicologia e em psicoterapia, que Frankl defende e justifica a proposta de humanização da terapia e da própria ciência psicológica. Acima de tudo, compreender os fundamentos epistemológicos da terapia do logos, e principalmente, clarificar o conceito de espírito e de espiritualidade em Frankl, faz-se essencial para o real entendimento da proposta logoterapêutica do ponto de vista ético, filosófico, psicológico e político; além de ser fundamental para que não ocorram atuações precipitadas e acusações infundadas a respeito da prática logoterápica e de sua visão de homem como pessoa espiritual.

Conhecer devidamente os significados e as implicações que a dimensão espiritual trás na constituição da Logoterapia demonstra-se, portanto, indispensável e imprescindível para o entendimento do pensamento de Viktor Frankl e para uma atuação responsável enquanto logoterapêuta. $\mathrm{O}$ apelo do pai da Logoterapia, ao longo do desenvolvimento de sua abordagem, foi pela tematização da humanidade potencialmente presente no homem. Sua luta foi pela humanização da psicoterapia e das práticas de saúde como um todo e pela ressignificação do conceito de humanismo, acrescentando sua qualidade eminentemente existencial. Este é o sentido do conceito de espírito em Logoterapia, este é o seu verdadeiro legado, seu valor e sua importância dentro da abordagem do sentido da vida.

\section{Referências}

Brentano, F. (1935). Psicologia desde um punto de vista empírico. Madrid: Revista de Occidente (Original publicado em 1874).

Buber, M. (2010). Eu e Tu. São Paulo: Centauro (Original publicado em 1923).

Frankl, V.E. (1989). Psicoterapia e Sentido Da Vida: Fundamentos de Logoterapia e Análise Existencial. São Paulo: Quadrante (Original publicado em 1946).

Frankl, V. E. (1990). A Questão do Sentido em Psicoterapia. Campinas: Papirus (Original publicado em 1981).

Frankl. V. E. (2005). Um Sentido para a Vida: Psicoterapia e Humanismo. São Paulo: Ideias \& Letras (Original publicado em 1978).

Frankl V. E. (2007). A Presença Ignorada de Deus. Petrópolis: Vozes (Original publicado em 1948).

Frankl. V. E. (2011). A Vontade de Sentido: Fundamentos e Aplicações da Logoterapia. São Paulo: Paulus (Original publicado em 1972). 
Frankl. V. E. (2012). Logoterapia e Análise Existencial: Textos de seis décadas. Rio de Janeiro: Forense Universitária (Original publicado em 1987).

Figueiredo, L. C. M., (2008). Matrizes do Pensamento Psicológico. Petrópolis: Vozes.

Fonseca, A. H. L. (s.d.). Interpretação FenomenológicoExistencial: Sobre o Sentido do Interpretativo na Concepção e Método da Psicologia e Psicoterapia FenomenológicoExistencial. Laboratório Experimental de Psicologia e Psicoterapia Fenomenológico Existencial. Disponível em: https://sites.google.com/site/eksistenciaescola/ eksistencia.

Fonseca, A. H. L. (2006). Para Uma Historia da Psicologia e da Psicoterapia Fenomenológico Existencial - Dita Humanista. Maceió: Pedang.

Gibran, K. (2010). O Profeta. Rio de Janeiro (SP): BestBolso (Original publicado em 1923).

Hartmann, N. (1975). New Ways of Ontology. Westport, Connecticut: Greenwood (Original publicado em 1949).

Heidegger, M. (2009). Ser e Tempo, Petrópolis: Vozes (Original publicado em 1927)

Husserl, E. (2008). A Ideia da Fenomenologia. São Paulo: Edições 70 (Original publicado em 1973).

Lima Neto, V. B. (2012). Morte e sentido da vida: Tanatologia e Logoterapia, um diálogo ontológico. Revista Logos e Existência. 1(1), 38-49.

Penna, A. G. (2001). Introdução a Psicologia Fenomenológica. Rio de Janeiro: Imago.

Scheler, M. (1986). Visão Filosófica do Mundo. São Paulo: Perspectiva (Original publicado em 1928).

Scheler, M. (2003). A Posição do Homem no Cosmos. Rio de Janeiro: Forense Universitária (Original publicado em 1928).

Zinker, J. (2007). Processo Criativo em Gestalt-Terapia. São Paulo: Summus.

Valdir Barbosa Lima Neto - Graduado em Psicologia pela Universidade Federal do Ceará. Coordenador pedagógico no Instituto Sherpa de Psicologia e Desenvolvimento Humano. Endereço Institucional: Instituto Sherpa de Psicologia e Desenvolvimento Humano. Av. Viena Weyne, 1167 (Cambeba), CEP: 60.822-180. Fortaleza, CE. E-mail: valdir@institutosherpa.com

Recebido em 01.03 .13 Primeira Decisão Editorial em 22.09.13 Segunda Decisão Editorial em 02.12.13 Aceito em 12.12.13 